\title{
Familiar taste induces higher dendritic levels of activity-regulated cytoskeleton-associated protein in the insular cortex than a novel one
}

\author{
Jean-Pascal Morin, ${ }^{1}$ Cesar Quiroz, ${ }^{1,3}$ Lucia Mendoza-Viveros, ${ }^{1}$ Victor Ramirez-Amaya, ${ }^{2,4}$ \\ and Federico Bermudez-Rattoni ${ }^{1,4}$ \\ ${ }^{1}$ División de Neurociencias, Instituto de Fisiología Celular, Universidad Nacional Autónoma de México, A.P. 70-253, 04510 México \\ D.F., México; ${ }^{2}$ Departamento de Neurobiología Conductual y Cognitiva, Instituto de Neurobiología, Universidad Nacional Autónoma \\ de México, Querétaro 76230, México
}

\begin{abstract}
The immediate early gene (IEG) Arc is known to play an important role in synaptic plasticity; its protein is locally translated in the dendrites where it has been involved in several types of plasticity mechanisms. Because of its tight coupling with neuronal activity, Arc has been widely used as a tool to tag behaviorally activated networks. However, studies examining the modulation of Arc expression during and after learning have yielded somewhat contradictory results. Although some have reported that higher levels of Arc were induced by initial acquisition of a task rather than by reinstating a learned behavior, others have failed to observe such habituation of Arc transcription. Moreover, most of these studies have focused on the mRNA and, surprisingly, relatively little is known about how learning can affect Arc protein expression levels. Here we used taste recognition memory and examined Arc protein expression in the insular cortex of rats at distinct times during taste memory formation. Interestingly, we found that more Arc protein was induced by a familiar rather than by a novel taste. Moreover, this increase was inhibited by post-trial intrahippocampal anisomycin injections, a treatment known to inhibit safe-taste memory consolidation. In addition, confocal microscopy analysis of immunofluorescence stained tissue revealed that the proportion of IC neurons expressing Arc was the same in animals exposed to novel and familiar taste, but Arc immunoreactivity in dendrites was dramatically higher in rats exposed to the familiar taste. These results provide novel insights on how experience affects cortical plasticity.
\end{abstract}

[Supplemental material is available for this article.]

Neural activity relevant for stimuli encoding and processing has been closely associated with an increased expression of immediate early genes (IEGs) within activated neurons (e.g., Campeau et al. 1991; Koya et al. 2009). For this reason they have long been used as a tool to tag neuronal populations activated by specific behaviors (Guzowski et al. 2005). One of these IEGs, Arc, which encodes the activity-regulated cytoskeleton-associated protein (Lyford et al. 1995) also known as Arg3.1 (Link et al. 1995), has been identified as an "effector" IEG whose expression is strongly induced by behaviorally relevant neural activity both in the hippocampus (Guzowski et al. 1999) and the cortex (RamirezAmaya et al. 2005). Importantly, it was shown that neurons that express Arc mRNA induced by a behavioral task also express the protein (Ramirez-Amaya et al. 2005). Arc protein is enriched in the neuronal soma and dendrites (Lyford et al. 1995) where it can be locally synthetized (Steward et al. 1998; Park et al. 2008). At the functional level, Arc has been shown to be essential for synaptic plasticity and memory consolidation (Guzowski et al. 2000;

\footnotetext{
${ }^{3}$ Present address: National Institute on Drug Abuse, Baltimore, MD 21224, USA.

${ }^{4}$ Corresponding authors.

E-mail fbermude@ifc.unam.mx.

E-mail vramirez1023@gmail.com.

Article is online at http://www.learnmem.org/cgi/doi/10.1101//m.2323411.
}

Plath et al. 2006) and to participate in homeostatic plasticity (Shepherd et al. 2006), as well as mGLUR1-dependent long-term depression (Park et al. 2008).

Evidence linking Arc mRNA expression and novelty/familiarity is rather unclear. Although some studies have directly linked increased Arc expression with the acquisition of a novel behavior (Kelly and Deadwyler 2002), many others failed to find such a relation. For example, one group found that Arc transcription did not habituate with overtraining in the spatial water-maze task (Guzowski et al. 2001). Yet another study found that the number of Arc expressing granule cells in the dentate gyrus were similar after the first or ninth exposure, suggesting that Arc mRNA expression in the dentate gyrus is not linked to the novelty of a sensorial experience (Chawla et al. 2005). Moreover, another study found that in CA3, the number of cells expressing Arc mRNA did not change regardless of the number of training trials or training days whereas in CA1, Arc mRNA was in fact increased once the trial had become familiar (Miyashita et al. 2009). Most strikingly, it was recently demonstrated that although c-fos expression was reduced after repeated pre-exposure to the same stressor, Arc responses failed to decrease in all but one of the studied areas (Ons et al. 2010). Fewer studies have focused on determining how much Arc protein levels can be affected by learning. One study reported that its levels went up in the frontal cortex after initial acquisition of a lever pressing task but were comparable to baseline after overtraining (Kelly and Deadwyler 2003). However, another group 
Taste familiarity correlates with enhanced dendritic Arc levels

using the Morris water maze found that Arc protein levels were still high after overtraining (Miyashita et al. 2008).

Familiarization with a gustatory stimulus that is not paired with gastric malaise is depending upon the formation of a safe taste memory trace (Bermudez-Rattoni 2004). Behaviorally, safe taste memory trace formation is observed by a gradual increase in the intake of flavored-water solution as a function of the number and the duration of prior periods of access to the solution and it was termed Attenuation of Neophobia (AN) (Domjan 1976) or safe Taste Recognition Memory (Bermudez-Rattoni 2004). Taste familiarization has been shown to be a gradual, updatable process dependent on several rounds of protein synthesis in the IC upon reactivation (Rodriguez-Ortiz et al. 2005). Also, it has been shown with a number of distinct methods that the activity of tasteresponsive neurons in the IC can be modified with learning (Yasoshima and Yamamoto 1998; Bahar et al. 2004; Accolla and Carleton 2008). Furthermore, AN is a simple task that induces minimum stress and for which a range of molecular mechanisms have been identified (Bermudez-Rattoni 2004). To further elucidate the plasticity events in IC circuitry during taste learning, we investigated how Arc protein expression levels changed depending upon the novelty or the familiarity of a taste. We found that higher Arc protein levels are observed in the IC once the taste became familiar. This increase was dependent upon previous formation of safe taste memory and appeared to be limited to the dendrites. Our results contrast with the classical memory consolidation hypothesis but are in agreement with the ideas proposed more recently, suggesting that plasticity may occur constantly and continuously, coupled to the animal's experience (Miyashita et al. 2008).

\section{Results}

We sought to determine if the amount of Arc detected in the IC of rats after taste ingestion varied depending on how familiar they were with this taste. In order to determine the post-stimulus time required to observe a detectable Arc expression in the IC after fluid ingestion we presented rats with novel saccharin and sacrificed them at 30, 60, or 240 min after the onset of fluid ingestion. Comparisons with one-way ANOVA revealed significant differences between the groups $\left(F_{(3,21)}=3.429, P<0.05\right)$. Fisher PLSD analysis showed that the $60 \mathrm{~min}$ group had significantly higher Arc levels than all others ( $P<0.05$ in all cases) (Fig. 1A, inset). Therefore, for the following experiments, comparisons were made at $60 \mathrm{~min}$ after the first (N), second (F2), and fifth (F5) saccharin presentation. Another group consisting of animals that drank water only (W) was also included. A one-way ANOVA revealed significant differences among the groups $\left(F_{(2,15)}=\right.$ 9.075, $P<0.001$ ) (Fig. 1). Fisher post hoc analysis revealed that Arc levels were significantly superior in F2 group than in $\mathrm{N}$ and W groups $(P<0.05)$. Further, F5 Arc levels were also significantly higher than that of the $\mathrm{N}(P<0.01)$ and $\mathrm{W}(P<0.01)$ groups, although the difference between the F2 and F5 groups did not reach significance $(P=0.16)$. Together, these data indicate that familiar saccharin consumption induced higher Arc expression in the IC than novel taste did (Fig. 1A). On the other hand, Arc levels in the DH were similar after familiar and novel saccharin intake and both did not differ from control levels $\left(F_{(2,13)}=0.414, P=\right.$ 0.67) (Fig. 1C).

Bilateral anisomycin injection in the $\mathrm{DH}$ after novel taste consumption has been shown to disrupt consolidation of AN (De la Cruz et al. 2008). We therefore wondered whether this treatment would also damper the increment of Arc observed on the second day of saccharin presentation (see Fig. 1A). With this in mind, we performed post-trial intrahippocampal anisomycin
A

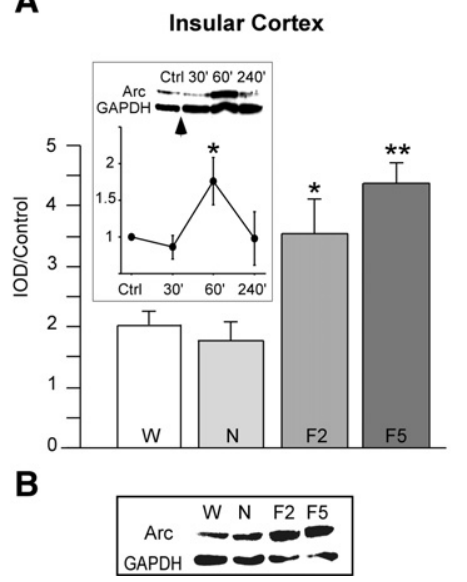

C

Dorsal Hippocampus

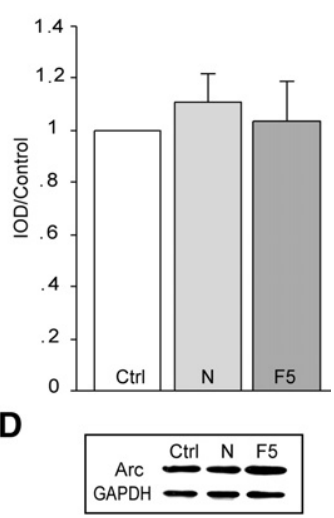

Figure 1. (A) Arc protein expression in the $\mathrm{IC}$ is higher after familiar (F2 and F5) rather than after novel (N) taste presentation, $n \geq 5$ per group; $\left(^{*}\right)$ $P<0.05,\left({ }^{*}\right) P<0.01$. Inset: The time course of Arc protein expression following novel saccharin intake. $(B)$ Representative blot of the analysis shown in $A$. (C) In the DH, Arc levels do not differ from control levels in both $\mathrm{N}$ and $\mathrm{F} 5$ groups. $(D)$ Representative blot of the analysis shown in C. Values are mean \pm SEM, plotted as proportion of control.

injections immediately after the novel saccharin ingestion session and measured IC Arc levels $1 \mathrm{~h}$ after the second saccharin presentation (F2) on the following day. Students $t$-test revealed a significant difference between anisomycin injected rats and those injected with vehicle $\left(t_{(12)}=2.263, P<0.05\right)$ (Fig. $2 \mathrm{~A}$ ). No difference was observed between the drug and vehicle groups when injections were performed the day before novel saccharin presentation $\left(t_{(8)}=0.003, P=0.99\right)$ (Fig. 2B). Additionally, anisomycin injections after familiar (F5) saccharin did not alter taste-induced IC Arc levels on the following day $\left(t_{(8)}=1.077, P=0.313\right.$ ) (Fig. 2C) indicating that DH anisomycin injections do not by themselves alter taste-induced IC Arc expression on the following day. Rather, these results suggest that optimal Arc expression in the IC after taste consumption is dependent upon previous familiarization with that same taste.

We next sought to evaluate: (1) the proportion of neurons in the IC expressing Arc after novel and familiar (fifth presentation) saccharin, and (2) the dendritic accumulation of the protein in both conditions. Early studies using neuroanatomical and electrophysiological techniques identified the dysgranular region of the IC as the gustatory cortex (Kosar et al. 1986a,b). Also, in vivo intrinsic imaging experiments showed that the anterior part of the IC responded best to taste modalities (Accolla et al. 2007). Further, a more recent study using neuronal activity mapping with Arc mRNA (Saddoris et al. 2009) indicates that the integration of taste-related information mostly occurs in the anterior dysgranular region of the IC. Finally, based on early electrophysiological evidence (Yamamoto et al. 1989), as well as in preliminary findings from our lab with Arc immunohistochemistry, we determined that layers IV/V best responded to taste stimulation. For these reasons, we decided to focus on the medial to deep layers of the dysgranular IC to perform our immunohistochemical analysis (Supplemental Fig. S2). We used double immunofluorescence vs. Arc and MAP-2 and nuclei counterstaining to compare (1) the proportions of Arc expressing neurons and (2) the dendritic expression of Arc in between the two conditions. Immunohistochemical detection of Arc in control animals revealed relatively low levels of staining $(7.52 \%$ Arc + neurons out of $244 \pm 42$ analyzed neurons/animal, $n=5$ ). Sparse, discrete units were detected, sometimes with dendritic immunoreactivity 
A
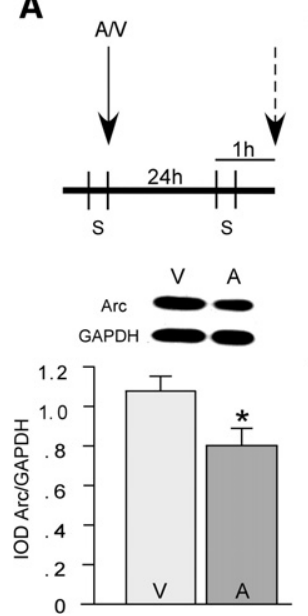

B
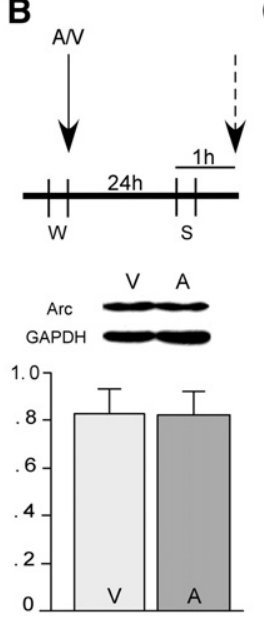

C
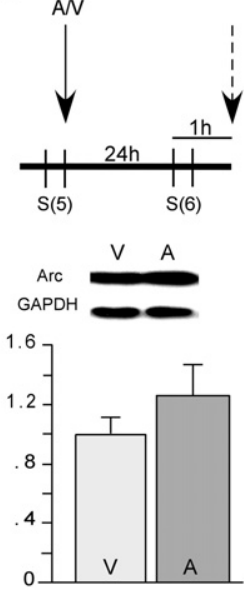

Figure 2. (A) Intrahippocampal bilateral anisomycin injections after novel taste consumption, a treatment known to inhibit AN, altered Arc expression in the IC induced by the second saccharin presentation (F2) (B) Intrahippocampal anisomycin injections $24 \mathrm{~h}$ before novel saccharin had no effect on IC Arc expression following Nov. (C) Injecting anisomycin in the hippocampus once the taste memory is consolidated (after F5) did not affect Arc expression in the IC induced by saccharin presentation on the following day. A, anisomycin; V, vehicle; W, water; S, saccharin; numbers between parentheses, days of saccharin presentation; $\left({ }^{*}\right) P<$ $0.05, n \geq 5$ in all groups. (Above) Scheme of the behavioral procedures, the dashed arrow represents the moment of sacrifice after which IC were processed for $W B$ analysis. Values are mean \pm SEM, plotted as IOD Arc/IOD GAPDH.

(data not shown). Cell counting analysis on saccharin-drinking animals revealed that on average, $22.28 \%$ of neurons were found to be Arc + after novel $(\mathrm{N})$ taste $(263 \pm 44$ neurons/animal, $n=5)$ and $20.67 \%$ after familiar (F5) taste (288 \pm 38 neurons/animal, $n=5$ ), both figures being very similar to what has been reported in other studies on taste learning that evaluated Arc mRNA levels (Barot et al. 2008; Saddoris et al. 2009). When comparing the percentage of neurons expressing Arc protein in both conditions, no difference was detected between N and F5 $\left(t_{(8)}=0.96, P=0.37\right)$, indicating that the same proportion of neurons were activated in the IC by a familiar and a novel taste stimulus (Fig. 3C). However, the area of Arc/MAP-2, colocalization was significantly greater in the familiar condition $\left(t_{(8)}=4.08, P<0.01\right)$ suggesting that a familiar taste-induced higher dendritic Arc expression (Fig. 3D). Also, the immunoreactive area for MAP-2 did not vary significantly between conditions $\left(t_{(8)}=0.38, P>0.71\right)$ (Fig. 3E). Finally, we used Manders' $M_{1}$ colocalization coefficient (see Materials and Methods) to confirm that the increase observed in the colocalization area was due to an increase in dendritic expression and not to a global increase in Arc immunoreactivity. As expected, averaged $M_{1}$ coefficients were significantly superior in the familiar condition $\left(t_{(8)}=3.09, P<0.05\right)$ indicating that in the IC, a greater amount of Arc protein was present in the dendrites after a familiar taste as compared to a novel one (Fig. 3F).

\section{Discussion}

Familiar saccharin consumption induced greater Arc protein levels in the IC than that induced by novel saccharin, whereas in the DH Arc protein expression was similar to basal levels in both conditions. Post-trial anisomycin infusion in the $\mathrm{DH}$ attenuated the increase of Arc expression in the IC observed after the second presentation of saccharin. Finally, we observed that the same proportion of cells expressed Arc protein in both conditions, but a

substantially greater dendritic accumulation was observed in the familiar condition.

Some studies evaluating the dynamics of expression of plasticity-related factors in the IC during taste learning have reported an increase in the expression of c-fos and PSD-95 in a time window following the presentation of a novel but not a familiar taste (Koh et al. 2003; Elkobi et al. 2008). These findings are consistent with a role of these plasticity-related factors in the consolidation of the information related to the novel stimulus. Combined with the earlier works that found that novel tasteinduced post-translational modifications (Rosenblum et al. 1997; Berman et al. 1998), they have led some investigators to propose that novel taste presentation represents by itself a onetrial learning, in which consolidation takes place during the hours following intake (Yefet et al. 2006). Our findings are in fact at odds with a role of de novo Arc protein synthesis in such a scenario. Should this be the case, one would expect to observe an increase in Arc protein expression after novel taste presentation, which would return to basal levels as the taste becomes familiar. Interestingly however, an earlier report found a persistent activation of Erk pathway in the IC after novel taste that was even more robust when the taste was familiar. This finding led the investigators to propose that persistent activation of the Erk pathway is
A

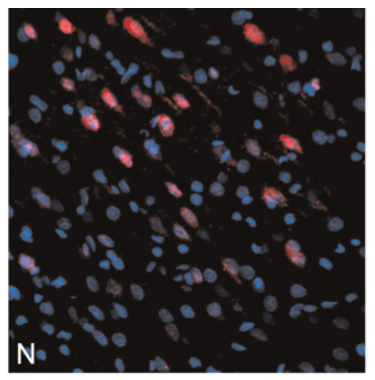

B

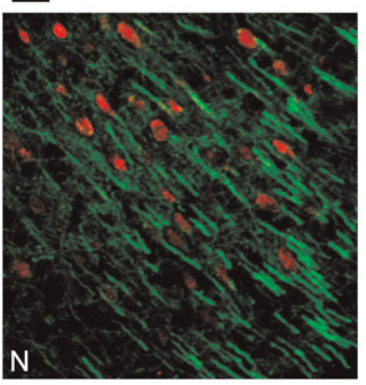

C
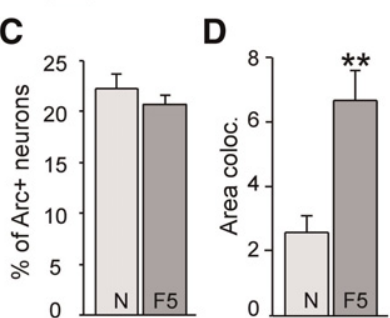
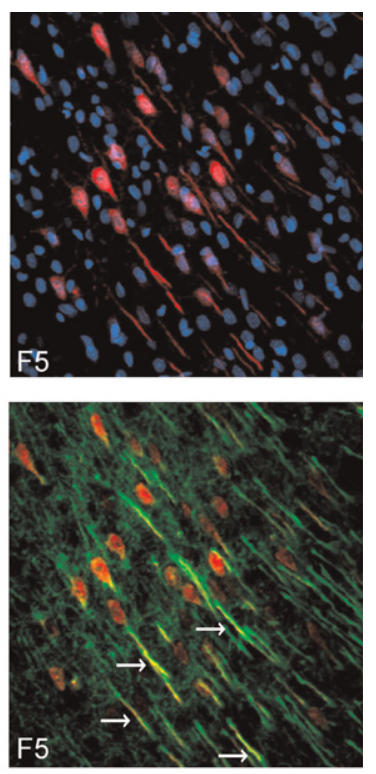

E

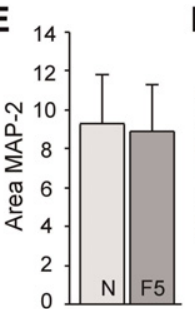

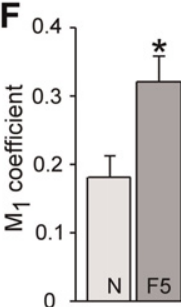

Figure 3. $(A, B)$ Representative images of Arc expression in the IC following novel $(\mathrm{N})$ and familiar $(\mathrm{F})$ taste presentation. Blue, DAPl; green, MAP-2; red, Arc. Colocalization Arc/MAP-2 appears as yellow (arrows). Scale bar on the bottom left represents $25 \mu \mathrm{m}$. (C) Percent of neurons expressing Arc protein in each condition; $n=5$ animals per condition. $\left(^{* *}\right) P<0.01$. (D) Dendritic accumulation of Arc protein expressed as the area of colocalization with MAP-2 in pixels. (**) $P<0.01$. (E) Averaged area of MAP-2 immunoreactivity. $(F) M_{1}$ colocalization coefficients; $n=5$ animals per condition. $\left(^{*}\right) P<0.05$. Values are mean \pm SEM. 
required for retention of taste memory (Swank and Sweatt 2001). As Arc is a downstream target of Erk (Waltereit et al. 2001), our data could be explained at least in part by this persistent MAPK activation. Additionally, an early study that used nonfluorescent in situ hybridization to analyze various areas of the brain after familiar vs. novel taste presentation found that in the cingulate cortex, the parietal cortex, and the dentate gyrus, more cells expressed Arc after novel saccharin than after familiar saccharin, although importantly they did not report any change in the IC (Montag-Sallaz et al. 1999). Our study extends these findings by showing that the proportion of cells that express the protein is also similar in both conditions, but also by revealing that these same cells have substantially more Arc, possibly more specifically in their dendrites. However, our results contrast with what was reported for c-fos, another IEG, after novel taste learning (Koh et al. 2003). Interestingly, it has been reported that c-fos but not arc expression rapidly decreases after repeated exposures to a stressor (Ons et al. 2010). This difference may explain the discrepancy between that and our study and it also shows that different IEGs may be reporting distinct phenomena.

Using multi-unit recording to assess the issue of how familiarity to a taste is processed and codified in the IC, one group of researchers found that when a familiar stimulus was presented, the average neuronal response was higher than that which followed novel taste presentation, suggesting that a "familiarity signature" had been established (Bahar et al. 2004). Interestingly, this increase is detected specifically throughout the late phase of the response, which overlaps with a time window during which palatability coding takes place (Katz et al. 2001). This strengthens the idea that this increased firing is indeed related to familiarity coding as familiarization with a taste induces a shift in its hedonic properties-the phenomenon of AN (Bermudez-Rattoni 2004). Given the strong correlation between Arc protein expression and neural activity (Lyford et al. 1995), and the numerous signalization pathways that can work in concert to increase ARC expression (Waltereit et al. 2001; Kawashima et al. 2009; Pintchovski et al. 2009), it is possible that different patterns of neural activity could induce variable amounts of Arc within a single cell and therefore explain the phenomenon we reported here. Alternatively it is possible that in our behavioral paradigm, the increased dendritic Arc protein is the product of local activation of mGLURI. These receptors have recently been shown to promote local translation of existing Arc transcripts, which is essential for mGLUR-dependent LTD. Moreover, Group I metabotropic receptors are Gq-coupled receptors known to play a role in object recognition memory (Lüscher and Huber 2010), a task that has been proposed to share mechanisms with safe taste recognition memory or AN (Bermudez-Rattoni 2004).

Now the obvious intrigue is why would more Arc be required after the presentation of a familiar stimulus? Could it serve any specific role in memory updating, stabilization, or reconsolidation? As mentioned previously, many diverse functions of Arc in plasticity have been reported such as a role in the maintenance phase of LTP (Guzowski et al. 2000), a role in mGLUR-dependent LTD (Park et al. 2008) and a role in homeostatic down-regulation of AMPA receptors (Chowdhury et al. 2006; Shepherd et al. 2006). In light of this, we could speculate that the increase in Arc protein we observe in the familiar condition would serve to homeostatically regulate gustatory neurons of the gustatory cortex that are repetitively activated by the presentation of the same stimulus. In this scheme, Arc would act as a homeostatic modulator of synaptic weights, stabilizing a memory trace every time it is reactivated. Alternatively, this proposed stabilization could occur in a metaplasticity-like fashion, as suggested earlier (Shepherd and Bear 2011), and serve to increase the threshold for further plasticity mechanisms to occur, thus making them less likely.
Interestingly, based on the data obtained with Arc mRNA and Arc protein expression dynamics briefly discussed earlier, it was recently suggested that plasticity events are still occurring when a behavior is reinstated (Miyashita et al. 2008). Our data are also in accordance with such a model and are also hard to reconcile with the "classic" memory consolidation hypothesis that sustains that once synaptic modifications that represent a memory trace are encoded and consolidated, the memory remains in an immutable stable state permanently. However, we cannot rule out that some reconsolidation process is occurring when a familiar taste is presented, even when a behavioral plateau has been reached and therefore, no further updating of the memory trace is necessary. Further experiments analyzing the behavioral consequences of directly or indirectly manipulating Arc protein levels during safe taste memory formation are needed to clarify this issue.

\section{Methods}

\section{Subjects}

All experimental animals were handled in accordance with the rules and guidelines of the local animal care committee. A total of 122 male Wistar rats weighing between 270 and $300 \mathrm{~g}$ were housed individually, maintained on a 12-h dark/light cycle, and given rat chow and water ad libitum until the beginning of the experiments.

\section{Behavioral procedures}

For all the duration of the behavioral procedures, access to drinking fluid was restricted to twice a day: a morning session of $15 \mathrm{~min}$, with volume restricted to $5 \mathrm{~mL}$, and an afternoon session of the same duration with unrestricted access to water, which served to properly hydrate the animals. The first $5 \mathrm{~d}$ of restricted access to fluid consisted of a habituation session during which animals were given water only. The restricted volume was set to $5 \mathrm{~mL}$ and the concentration to $0.5 \%$ based on previous studies on taste learning (Rosenblum et al. 1997; Bernstein and Koh 2007) and confirmed by our behavioral data (Supplemental Fig. S1). This was done to avoid significant differences between the groups in the amount of liquid ingested that is characteristic of AN. Our volume restriction protocol did not affect familiarization with the taste and by the fifth presentation of saccharin, a behavioral plateau was reached in both restricted and unrestricted AN protocols (see Supplemental Fig. S1).

For the first experiment aimed at establishing the time course of arc expression after fluid intake, rats were given novel saccharin and killed at 30,60, or 240 min after the beginning of the drinking session. A control group consisting of water-deprived animals that received no taste stimulation was also included. The following experiments were aimed at evaluating if taste-induced Arc protein expression in the IC was affected by the degree of familiarization with the taste. Rats were divided into three saccharin-drinking groups (novel, familiar 2, and familiar 5) in addition to a water group and the control group mentioned previously (Ctrl). The novel (N) group drank water on days 6-9, and on day 10 the daily water ration was replaced by a $0.5 \%$ solution of sodium saccharin. The familiar 2 (F2) group was given the saccharin solution instead of water on days 9 and 10 . The familiar (F5) group was given saccharin solution instead of water from days $6-10$. Finally, the water group (W) was given only water up to day 10 . All animals of this experiment were sacrificed $1 \mathrm{~h}$ after the beginning of the drinking session of day 10 and processed for Western blot or immunohistochemistry. Note that by systematically restricting the volume to $5 \mathrm{~mL}$, we ensured that all animals drank the same amount of the saccharin solution $1 \mathrm{~h}$ before being sacrificed, the only difference between the groups being how familiar they were with the taste.

For the anisomycin experiment, intrahippocampal anisomycin/vehicle injections were performed either $24 \mathrm{~h}$ before novel saccharin presentation after water drinking, immediately after 
novel saccharin, or immediately after familiar saccharin. On the day following the injection, animals were presented saccharin and sacrificed.

\section{Western blotting}

Insular cortices from both hemispheres were carefully dissected and quickly immersed in $200 \mu \mathrm{L}$ of lysis buffer containing $50 \mathrm{mM}$ Tris- $\mathrm{HCl}, 150 \mathrm{mM} \mathrm{NaCl}, 1 \%$ Nonidet NP-40, 1\% SDS, full protease inhibitors (Roche Applied Biosystems), $5 \mathrm{mM} \mathrm{NaF}$ and $2 \mathrm{mM}$ Na3VO 4 and homogenized by sonication. The resulting homogenates were centrifuged at $1500 \mathrm{~g}$ for $10 \mathrm{~min}$ at $4 \mathrm{C}^{\circ}$ and frozen at $-80^{\circ} \mathrm{C}$ until processed. Equal volumes of homogenate from each condition were subjected to $10 \%$ SDS-PAGE at $125 \mathrm{~V}$ for $65 \mathrm{~min}$ and proteins were transferred to Immobilon-P membranes (Bio-Rad) at $25 \mathrm{~V}$ for $40 \mathrm{~min}$. The membranes were then blocked overnight at $4^{\circ} \mathrm{C}$ with TBST buffer (Tris $10 \mathrm{mM}$, $\mathrm{NaCl} 0.9 \%$, Tween-20 $0.2 \%$, pH 7.5 ) with $5 \%$ bovine serum albumin. On the following day, membranes were incubated in blocking buffer containing affinity purified rabbit anti-Arc polyclonal antibody (1:500; Synaptic Systems) during $90 \mathrm{~min}$, then washed ( 4 times/7 min in TBST) and put in a 1:20,000 solution of HRP-goat anti-rabbit (Invitrogen) for $1 \mathrm{~h}$. After washing, membranes were incubated for another hour in 1:10,000 in mouse anti-Glyceraldehyde 3-phosphate dehydrogenase (GAPDH) (Chemicon) in blocking buffer, washed again and then incubated for $45 \mathrm{~min}$ in HRP-goat anti-mouse (Zymed) at 1:20,000 in TBST. Chemiluminescent reaction was then carried out with the SuperSignal West Pico Substrate kit (Thermo Fisher Scientific) following the manufacturer's instructions. The reaction was then exposed to photographic films that were subsequently digitalized. Integrated optical densities of blots were quantified using $\mathrm{NIH}$ software ImageJ (Wayne Rasband, National Institutes of Health).

\section{Surgical procedures and drug injections}

Rats were deeply anesthetized with ketamine:xylazine $(22: 2.6 \mathrm{mg} / \mathrm{rat})$ and secured on a stereotaxic frame. Cannulas were implanted in the DH using the following coordinates: AP. 3.6, Lat. \pm 3, V. $1.3 \mathrm{~mm}$ from bregma according to a rat brain atlas (Paxinos and Watson 2007). Two 5-mm screws were fixed to the skull with dental acrylic cement to help stabilize the cannulas. Animals were then allowed to recover for at least one week before the beginning of the experimental procedures. Rats were gently handled for $3 \mathrm{~d}$ before the injection took place in order to minimize stress. On the day of the injection, injector tips were aimed $2 \mathrm{~mm}$ below the ends of the cannulas and the drug was infused in each hemisphere at a $1 \mu \mathrm{L} / \mathrm{min}$ infusion rate. Anisomycin (Sigma) was dissolved in equimolar $\mathrm{HCl}$ and adjusted to $120 \mu \mathrm{g} /$ $\mu \mathrm{L}, \mathrm{pH} 7.4$ in vehicle solution (ACSF [mM]: $125 \mathrm{NaCl}, 5 \mathrm{KCl}$, $1.25 \mathrm{NaH}_{2} \mathrm{PO}_{4} \mathrm{H}_{2} \mathrm{O}, 1.5 \mathrm{MgSO}_{4} 7 \mathrm{H}_{2} \mathrm{O}, 26 \mathrm{NaHCO}_{3}, 10$ glucose, $2.5 \mathrm{CaCl}_{2}$ ).

\section{Immunohistochemistry}

Rats were perfused with a saline solution with heparin at body temperature for $<5 \mathrm{~min}$ and then with ice-cold formaldehyde solution at $4 \%$ in $0.1 \mathrm{M}$ phosphate buffer. Whole brains were dissected and stored at $4^{\circ} \mathrm{C}$ in $30 \%$ sucrose in $0.15 \mathrm{M}$ phosphate buffer containing $0.9 \mathrm{NaCl}$ (PBS) until they sank. Twenty-micrometer coronal slices situated at the level of the gustatory insular cortex were then cut with a microtome maintained cold with a $\mathrm{CO}_{2}$ pump. Slices were recovered in PBS and immediately processed for double immunohistochemistry. Briefly, free-floating sections were rinsed and soaked in PBS with $1 \% \mathrm{NaBH} 4$ for $8 \mathrm{~min}$. Sections were then washed abundantly and incubated in a blocking buffer consisting of 5\% BSA and $0.3 \%$ Triton in PBS during $1 \mathrm{~h}$. Then, sections were incubated in 1:1000 polyclonal rabbit anti-Arc 1:1000 (generous gift from Paul Worley's laboratory); 1:250 monoclonal mouse anti-Microtubule associated protein $2 \mathrm{a}, \mathrm{b}$ (Chemicon) in the blocking buffer during $38 \mathrm{~h}$ at $4^{\circ} \mathrm{C}$ followed by $30 \mathrm{~min}$ at room temperature. Posteriorly, sections were washed and incubated in 1:500 Alexa594 goat anti-rabbit (Invitrogen); 1:200 FITC-coupled goat-anti-mouse (Chemicon) in PBS with $0.3 \%$ triton. Sections were then washed, counterstained with 4',6-diamidino-2-phenylindole (DAPI). Slices were then protected with a Vectashield mounting medium (Vector Laboratories), cover-slipped, and sealed with nail polish. Note that the two Arc primary antibodies that we used yielded very similar staining and the same immunoblot band at $\sim 58 \mathrm{kDa}$ (data not shown).

\section{Confocal microscopy}

A Zeiss LSM 510 META microscope equipped with a multiphoton Chameleon laser (Coherent) set at $750 \mathrm{~nm}$, a HeNe laser at $561 \mathrm{~nm}$, and an argon at $488 \mathrm{~nm}$ was used to obtain Z-section images of the immunostained tissue. All settings were optimized using the first section on every slide, which belonged to a control animal. These settings were then maintained constant for the remaining sections on the same slide (which corresponded to one immunohistochemistry run). One capture of every condition was performed during the same day in order to diminish possible variation in the apparatus (Hibbs 2004). Z-stacks had $0.55-\mu \mathrm{m}$ optical thickness and were collected with a 40X oil-immersion objective with 1.3 N.A. For each subject, images were captured at layers IV and V of the dysgranular IC from at least three different slices located between 1.2 and $1.7 \mathrm{~mm}$ anterior to bregma. The mosaic presented in Figure 3 was captured with a Zeiss Apotome microscope and represents the region where the images were taken.

\section{Image analysis}

All analyses were performed using NIH ImageJ software. For each slide, experimental conditions were assigned a code for the experimenters to perform a blind analysis. Cells were classified as neuronal or non-neuronal, by visualizing them through the whole image stack. Cells with small intensely bright and uniformly stained nuclei, as revealed with DAPI, can be identified as nonneuronal (Vazdarjanova and Guzowski 2004) and were therefore excluded from the analysis. All nuclei with shaded, heterogeneous staining that could be identified as pertaining to neurons (Vazdarjanova and Guzowski 2004) were included in every 40X image stack. Nuclei included in the analysis were those detected in the medial plane of the z-stack as described earlier (Ramirez-Amaya et al. 2005) and averaged $\sim 54$ neurons per stack. We then analyzed the proportion of Arc + neurons as described previously (Ramirez-Amaya et al. 2005). For colocalization analysis, Z-projections were performed and an automatic contrast was applied to each channel for each conditions. A "median" filter (1 pixel radius) was systematically applied to each stack as recommended when analyzing colocalization in large samples with relatively low resolution (Landmann and Marbet 2004). Total colocalization area was obtained using a colocalization plugin (Bourdoncle 2003). MAP-2 immunoreactive areas were calculated from binary images obtained from original Z-projections. Manders' $M_{1}$ colocalization coefficients (Manders et al. 1993) were obtained using a JaCoP plug-in (Bolte and Cordelieres 2006). In our case, the $M_{1}$ colocalization coefficient was obtained after establishing an automatic threshold and it indicates the proportion of red pixels (immunoreactivity to Arc) that colocalizes with green pixels (immunoreactivity to MAP-2) according to the following formula:

$$
M_{1}=\frac{\sum_{i} \text { red }_{i, \mathrm{coloc}}}{\sum_{i} \text { red }_{i}}
$$

\section{Statistical analysis}

Kolmogorov-Smirnov tests were conducted in all individual groups to test for normal distribution of the data. Where indicated, one-way ANOVA with Fisher's post hoc test and unpaired Students $t$-tests were performed to test for statistical significance $(P$ values $<0.05)$. All statistical analyses were conducted using StatView software. 


\section{Acknowledgments}

This work was supported by CONACYT 60478 (to F.B.R.) and 51028 (to V.R.A.) and PAPIIT IN216709 (to F.B.R.) and IN213907 (to V.R.A.). We thank Perla Moreno Castilla, Israela Balderas, and Elsa Nydia Hernández-Ríos for high-quality technical assistance. J.P.M. received a scholarship from the Coordinación de Estudios de Posgrado of Universidad Nacional Autónoma de México (UNAM). This study was performed in partial fulfillment of J.P.M.'s requirements for a doctorate degree in Biomedical Sciences at UNAM.

\section{References}

Accolla R, Carleton A. 2008. Internal body state influences topographical plasticity of sensory representations in the rat gustatory cortex. Proc Natl Acad Sci 105: 4010-4015.

Accolla R, Bathellier B, Petersen CC, Carleton A. 2007. Differential spatial representation of taste modalities in the rat gustatory cortex. J Neurosci 27: $1396-1404$.

Bahar A, Dudai Y, Ahissar E. 2004. Neural signature of taste familiarity in the gustatory cortex of the freely behaving rat. J Neurophysiol 92: 3298-3308.

Barot SK, Kyono Y, Clark EW, Bernstein IL. 2008. Visualizing stimulus convergence in amygdala neurons during associative learning. Proc Natl Acad Sci 105: 20959-20963.

Berman DE, Hazvi S, Rosenblum K, Seger R, Dudai Y. 1998. Specific and differential activation of mitogen-activated protein kinase cascades by unfamiliar taste in the insular cortex of the behaving rat. J Neurosci 18: 10037-10044

Bermudez-Rattoni F. 2004. Molecular mechanisms of taste-recognition memory. Nat Rev Neurosci 5: 209-217.

Bernstein IL, Koh MT. 2007. Molecular signaling during taste aversion learning. Chem Senses 32: 99-103.

Bolte S, Cordelieres FP. 2006. A guided tour into subcellular colocalization analysis in light microscopy. J Microsc 224: 213-232.

Bourdoncle P. 2003. Colocalization plugin in Java. Institut Jacques Monod, Service Imagerie, Paris, France.

Campeau S, Hayward MD, Hope BT, Rosen JB, Nestler EJ, Davis M. 1991. Induction of the $c$-fos proto-oncogene in rat amygdala during unconditioned and conditioned fear. Brain Res 565: 349-352.

Chawla MK, Guzowski JF, Ramirez-Amaya V, Lipa P, Hoffman KL, Marriott LK, Worley PF, McNaughton BL, Barnes CA. 2005. Sparse, environmentally selective expression of Arc RNA in the upper blade of the rodent fascia dentata by brief spatial experience. Hippocampus 15: $579-586$.

Chowdhury S, Shepherd JD, Okuno H, Lyford G, Petralia RS, Plath N, Kuhl D, Huganir RL, Worley PF. 2006. Arc/Arg3.1 interacts with the endocytic machinery to regulate AMPA receptor trafficking. Neuron 52: $445-459$.

De la Cruz V, Rodriguez-Ortiz CJ, Balderas I, Bermudez-Rattoni F. 2008. Medial temporal lobe structures participate differentially in consolidation of safe and aversive taste memories. Eur J Neurosci 28: $1377-1381$

Domjan M. 1976. Determinants of the enhancement of flavored-water intake by prior exposure. J Exp Psychol 2: 17-27.

Elkobi A, Ehrlich I, Belelovsky K, Barki-Harrington L, Rosenblum K. 2008. ERK-dependent PSD-95 induction in the gustatory cortex is necessary for taste learning, but not retrieval. Nat Neurosci 11: 1149-1151.

Guzowski JF, McNaughton BL, Barnes CA, Worley PF. 1999. Environment-specific expression of the immediate-early gene Arc in hippocampal neuronal ensembles. Nat Neurosci 2: 1120-1124.

Guzowski JF, Lyford GL, Stevenson GD, Houston FP, McGaugh JL, Worley PF, Barnes CA. 2000. Inhibition of activity-dependent arc protein expression in the rat hippocampus impairs the maintenance of long-term potentiation and the consolidation of long-term memory. J Neurosci 20: 3993-4001.

Guzowski JF, Setlow B, Wagner EK, McGaugh JL. 2001. Experiencedependent gene expression in the rat hippocampus after spatial learning: A comparison of the immediate-early genes Arc, c-fos, and zif268. J Neurosci 21: 5089-5098.

Guzowski JF, Timlin JA, Roysam B, McNaughton BL, Worley PF, Barnes CA. 2005. Mapping behaviorally relevant neural circuits with immediate-early gene expression. Curr Opin Neurobiol 15: 599-606.

Hibbs AR. 2004. Confocal microscopy for biologists. Springer, New York.

Katz DB, Simon SA, Nicolelis MA. 2001. Dynamic and multimodal responses of gustatory cortical neurons in awake rats. J Neurosci 21: 4478-4489.
Kawashima T, Okuno $\mathrm{H}$, Nonaka M, Adachi-Morishima A, Kyo N, Okamura M, Takemoto-Kimura S, Worley PF, Bito H. 2009. Synaptic activity-responsive element in the Arc/Arg3.1 promoter essential for synapse-to-nucleus signaling in activated neurons. Proc Natl Acad Sci 106: 316-321.

Kelly MP, Deadwyler SA. 2002. Acquisition of a novel behavior induces higher levels of Arc mRNA than does overtrained performance. Neuroscience 110: 617-626.

Kelly MP, Deadwyler SA. 2003. Experience-dependent regulation of the immediate-early gene Arc differs across brain regions. J Neurosci 23: $6443-6451$.

Koh MT, Wilkins EE, Bernstein IL. 2003. Novel tastes elevate c-fos expression in the central amygdala and insular cortex: Implication for taste aversion learning. Behav Neurosci 117: 1416-1422.

Kosar E, Grill HJ, Norgren R. 1986a. Gustatory cortex in the rat. I. Physiological properties and cytoarchitecture. Brain Res 379: 329-341.

Kosar E, Grill HJ, Norgren R. 1986b. Gustatory cortex in the rat. II. Thalamocortical projections. Brain Res 379: 342-352.

Koya E, Golden SA, Harvey BK, Guez-Barber DH, Berkow A, Simmons DE, Bossert JM, Nair SG, Uejima JL, Marin MT, et al. 2009. Targeted disruption of cocaine-activated nucleus accumbens neurons prevents context-specific sensitization. Nat Neurosci 12: 1069-1073.

Landmann L, Marbet P. 2004. Colocalization analysis yields superior results after image restoration. Microsc Res Tech 64: 103-112.

Link W, Konietzko U, Kauselmann G, Krug M, Schwanke B, Frey U, Kuhl D. 1995. Somatodendritic expression of an immediate early gene is regulated by synaptic activity. Proc Natl Acad Sci 92: 5734-5738.

Lüscher C, Huber KM. 2010. Group 1 mGluR-dependent synaptic long-term depression: Mechanisms and implications for circuitry and disease. Neuron 65: 445-459.

Lyford GL, Yamagata K, Kaufmann WE, Barnes CA, Sanders LK, Copeland NG, Gilbert DJ, Jenkins NA, Lanahan AA, Worley PF. 1995. $A r c$, a growth factor and activity-regulated gene, encodes a novel cytoskeleton-associated protein that is enriched in neuronal dendrites. Neuron 14: 433-445.

Manders EMM, Verbeek FJ, Aten JA. 1993. Measurement of colocalization of objects in dual-colour confocal images. J Microsc 169: 375-382.

Miyashita T, Kubik S, Lewandowski G, Guzowski JF. 2008. Networks of neurons, networks of genes: An integrated view of memory consolidation. Neurobiol Learn Mem 89: 269-284.

Miyashita T, Kubik S, Haghighi N, Steward O, Guzowski JF. 2009. Rapid activation of plasticity-associated gene transcription in hippocampal neurons provides a mechanism for encoding of one-trial experience. J Neurosci 29: 898-906.

Montag-Sallaz M, Welzl H, Kuhl D, Montag D, Schachner M. 1999. Novelty-induced increased expression of immediate-early genes $c$-fos and arg 3.1 in the mouse brain. I Neurobiol 38: 234-246.

Ons S, Rotllant D, Marin-Blasco IJ, Armario A. 2010. Immediate-early gene response to repeated immobilization: Fos protein and arc mRNA levels appear to be less sensitive than $c$-fos mRNA to adaptation. Eur J Neurosci 31: $2043-2052$.

Park S, Park JM, Kim S, Kim JA, Shepherd JD, Smith-Hicks CL, Chowdhury S, Kaufmann W, Kuhl D, Ryazanov AG, et al. 2008. Elongation factor 2 and fragile $\mathrm{X}$ mental retardation protein control the dynamic translation of Arc/Arg3.1 essential for mGluR-LTD. Neuron 59: 70-83.

Paxinos G, Watson C. 2007. The rat brain in stereotaxic coordinates, 6 th ed. Academic, San Diego, CA.

Pintchovski SA, Peebles CL, Kim HJ, Verdin E, Finkbeiner S. 2009. The serum response factor and a putative novel transcription factor regulate expression of the immediate-early gene $\operatorname{Arc} / \operatorname{Arg} 3.1$ in neurons. $J$ Neurosci 29: 1525-1537.

Plath N, Ohana O, Dammermann B, Errington ML, Schmitz D, Gross C, Mao X, Engelsberg A, Mahlke C, Welzl H, et al. 2006. Arc/Arg3.1 is essential for the consolidation of synaptic plasticity and memories. Neuron 52: 437-444.

Ramirez-Amaya V, Vazdarjanova A, Mikhael D, Rosi S, Worley PF, Barnes CA. 2005. Spatial exploration-induced Arc mRNA and protein expression: Evidence for selective, network-specific reactivation. J Neurosci 25: 1761-1768.

Rodriguez-Ortiz CJ, De la Cruz V, Gutierrez R, Bermudez-Rattoni F. 2005 Protein synthesis underlies post-retrieval memory consolidation to a restricted degree only when updated information is obtained. Learn Mem 12: 533-537.

Rosenblum K, Berman DE, Hazvi S, Lamprecht R, Dudai Y. 1997. NMDA receptor and the tyrosine phosphorylation of its $2 \mathrm{~B}$ subunit in taste learning in the rat insular cortex. J Neurosci 17: 5129-5135.

Saddoris MP, Holland PC, Gallagher M. 2009. Associatively learned representations of taste outcomes activate taste-encoding neural ensembles in gustatory cortex. J Neurosci 29: 15386-15396.

Shepherd JD, Bear MF. 2011. New views of Arc, a master regulator of synaptic plasticity. Nat Neurosci 14: 279-284. 
Taste familiarity correlates with enhanced dendritic Arc levels

Shepherd JD, Rumbaugh G, Wu J, Chowdhury S, Plath N, Kuhl D, Huganir RL, Worley PF. 2006. Arc/Arg3.1 mediates homeostatic synaptic scaling of AMPA receptors. Neuron 52: 475-484.

Steward O, Wallace CS, Lyford GL, Worley PF. 1998. Synaptic activation causes the mRNA for the IEG Arc to localize selectively near activated postsynaptic sites on dendrites. Neuron 21: 741-751.

Swank MW, Sweatt JD. 2001. Increased histone acetyltransferase and lysine acetyltransferase activity and biphasic activation of the ERK/RSK cascade in insular cortex during novel taste learning. J Neurosci 21: 3383-3391.

Vazdarjanova A, Guzowski JF. 2004. Differences in hippocampal neuronal population responses to modifications of an environmental context: Evidence for distinct, yet complementary, functions of CA3 and CA1 ensembles. J Neurosci 24: 6489-6496.

Waltereit R, Dammermann B, Wulff P, Scafidi J, Staubli U, Kauselmann G, Bundman M, Kuhl D. 2001. Arg3.1/Arc mRNA induction by $\mathrm{Ca}^{2+}$ and cAMP requires protein kinase $\mathrm{A}$ and mitogen-activated protein kinase/extracellular regulated kinase activation. J Neurosci 21: 5484-5493.

Yamamoto T, Matsuo R, Kiyomitsu Y, Kitamura R. 1989. Taste responses of cortical neurons in freely ingesting rats. J Neurophysiol 61: $1244-1258$.

Yasoshima Y, Yamamoto T. 1998. Short-term and long-term excitability changes of the insular cortical neurons after the acquisition of taste aversion learning in behaving rats. Neuroscience $\mathbf{8 4}$ : $1-5$.

Yefet K, Merhav M, Kuulmann-Vander S, Elkobi A, Belelovsky K, Jacobson-Pick S, Meiri N, Rosenblum K. 2006. Different signal transduction cascades are activated simultaneously in the rat insular cortex and hippocampus following novel taste learning. Eur J Neurosci 24: $1434-1442$.

Received June 21, 2011; accepted in revised form July 19, 2011. 


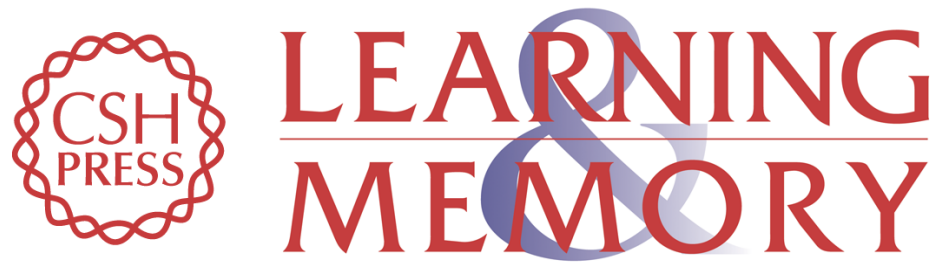

\section{Familiar taste induces higher dendritic levels of activity-regulated cytoskeleton-associated protein in the insular cortex than a novel one}

Jean-Pascal Morin, Cesar Quiroz, Lucia Mendoza-Viveros, et al.

Learn. Mem. 2011, 18:

Access the most recent version at doi:10.1101//m.2323411

Supplemental http://learnmem.cshlp.org/content/suppl/2011/09/15/18.10.610.DC1

Material

References This article cites 51 articles, 19 of which can be accessed free at: http://learnmem.cshlp.org/content/18/10/610.full.html\#ref-list-1

License

Email Alerting Receive free email alerts when new articles cite this article - sign up in the box at the Service top right corner of the article or click here. 